\title{
Kentron
}

Revue pluridisciplinaire du monde antique

18 | 2002

Le statut et l'image du corps dans la mythologie et la littérature grecques

\section{Le corps du Christ dans le Christos paschôn : imaginaire tragique, imaginaire chrétien}

\section{Michelle Lacore}

\section{OpenEdition}

\section{Journals}

Édition électronique

URL : http://journals.openedition.org/kentron/1978

DOI : 10.4000/kentron.1978

ISSN : 2264-1459

Éditeur

Presses universitaires de Caen

Édition imprimée

Date de publication : 31 décembre 2002

Pagination : 93-115

ISBN : 2-84133-202-0

ISSN : 0765-0590

\section{Référence électronique}

Michelle Lacore, « Le corps du Christ dans le Christos paschôn : imaginaire tragique, imaginaire chrétien », Kentron [En ligne], 18 | 2002, mis en ligne le 01 octobre 2018, consulté le 19 novembre 2020. URL : http://journals.openedition.org/kentron/1978 ; DOI : https://doi.org/10.4000/kentron.1978

\section{(c) (i) (2) $\Theta$}

Kentron is licensed under a Creative Commons Attribution-NonCommercial-NoDerivatives 3.0 International License. 


\section{LE CORPS DU CHRIST DANS LE CHRISTOS PASCHÔN: IMAGINAIRE TRAGIQUE, IMAGINAIRE CHRÉTIEN ${ }^{1}$}

\section{Authenticité de l'œuvre et lecture proposée}

Le poème dramatique auquel son premier éditeur humaniste (l'imprimeur

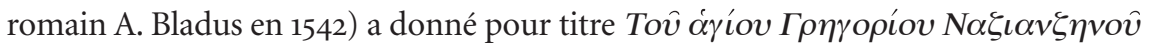

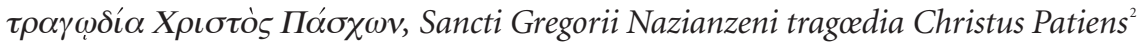
expose en 2602 vers $^{3}$ la passion et la mort du Christ, puis sa mise au tombeau et enfin sa résurrection. Ce drame comporte une proportion considérable - près des deux tiers de l'œuvre - de vers ou d'éléments de vers empruntés à diverses tragédies, essentiellement d'Euripide ${ }^{4}$.

Cet ensemble monumental, équivalent d'une trilogie liée, est donc un exemple remarquable de l'art du «centon », manifestation extrême de l'intertextualité, souvent assez sévèrement jugée comme forme littéraire, et qui ne fournit pas de critères internes de datation : l'exercice semble avoir été pratiqué, plus ou moins, à toutes

1. Communication prononcée le mercredi 9 mai 2001.

2. L'œuvre, qui nous est parvenue sans titre dans la tradition manuscrite, sera désignée ici par la forme translittérée du titre grec forgé par les humanistes (en abrégé Ch. P.). La Passion du Christ est le titre retenu par A. Tuilier dans son édition critique du poème de Grégoire de Nazianze, avec introduction, traduction, notes et index (Paris, Éditions du Cerf (Sources chrétiennes; n 149), 1969), qui est notre ouvrage de référence. L'auteur a donné une impulsion vigoureuse à une réévaluation de l'œuvre, favorable à la thèse de son authenticité. Les traductions reproduites entre guillemets proviennent de cette édition, avec parfois quelques modifications signalées. Les traductions sans guillemets sont nôtres. Nous nous sommes aidée de la traduction italienne de F. Trisoglio, La Passione di Cristo, Rome, Città nuova editrice, 1979.

3. Au drame proprement dit, précédé d'une préface en 30 vers, succède une prière au Christ et à la Vierge, qui occupe les 70 vers finaux et qui puise encore dans Euripide.

4. Au total 1554 vers du Ch. P. sur un total de 2602 comportent des emprunts à Euripide, d'extension variable, parfois tout un vers, parfois un mot seulement. L'index précieux d'A. Tuilier, p. 343-355, relève et classe les emprunts en fonction des tragédies concernées; nous avons utilisé pour cet article une mise en parallèle du texte du centon et des vers originaux, réalisée, à partir de l'index d'A. Tuilier, en collaboration avec S. Tailleur et J.-M. Mathieu pour la préparation du colloque de 1989, voir note 10. Notre total tient compte du fait que 67 vers au moins combinent des éléments empruntés à des pièces différentes. Ont été relevés aussi 33 vers empruntés à Eschyle (Agamemnon et Prométhée) et 11 à l'Alexandra de Lycophron. 
les époques. Les éditeurs modernes en détectent la présence dans le corpus hésiodique ou théognidéen ${ }^{5}$ et l'on voit les scholiastes peiner à distinguer l'art du centon (ou centrôn) - objet de leur mépris - de ce qu'ils appellent la « rhapsodie» homérique et qui est une première intuition du «style formulaire $»^{6}$. Le procédé stylistique du centon, bien distinct des recherches de réécriture des poètes alexandrins? connut une vogue certaine dans l'Antiquité tardive ${ }^{8}$, mais ne fut pas inconnu non plus de l'époque byzantine.

Les érudits qui ont, depuis le Xvi siècle, peu à peu dressé l'inventaire ${ }^{9}$ des emprunts faits par le poète chrétien à la tragédie d'Euripide, n'en ont cependant tiré aucun argument décisif pour trancher la question de l'authenticité de l'œuvre ${ }^{10}$, soulevée pour des raisons très diverses, par certains humanistes. A. Tuilier s'est le premier intéressé conjointement à l'authenticité grégorienne du centon et à la tradition du texte d'Euripide, faisant observer que, si les plus anciens manuscrits du

5. Voir les remarques de J. Carrière à propos des vers 1104-1106 du corpus théognidéen dans Théognis (Paris, Les Belles Lettres (CUF), 1975) et de P. Mazon dans Hésiode (Paris, Les Belles Lettres (CUF), 1928), à propos des vers 847-854 de la Théogonie ainsi que des vers 405 sq. du Bouclier.

6. Un passage des scholies londoniennes à Denys de Thrace est significatif à cet égard : 'P $\alpha \psi \omega \delta$ ó $\alpha v$ $\delta \dot{\varepsilon}$

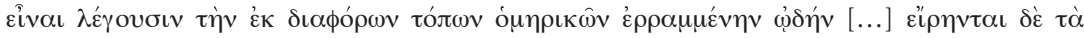

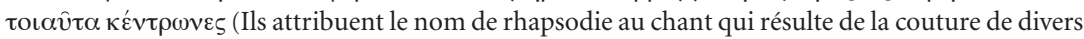
passages homériques [suit un exemple de centon assemblant six vers homériques de contextes très divers] ; mais ce genre de choses porte le nom de centon).

7. Voir par exemple C. Cusset, "Théocrite, lecteur d'Euripide : l'exemple des Bacchantes ", REG 110, 1997 , p. 454-468.

8. A. Tuilier a étudié ce développement de l'art du centon au $\mathrm{IV}^{\mathrm{e}}$ et au $\mathrm{v}^{\mathrm{c}}$ siècles dans son article « La datation et l'attribution du Christos Paschôn et l'art du centon », in Actes du ví Congrès international d'études byzantines (Paris, 1948), vol. I, Paris, Office des éditions universitaires, 1950, p. 403-409.

9. Inventaire jamais achevé d'ailleurs, en raison en particulier du nombre de tragédies perdues. Mais, même dans les œuvres conservées, on peut encore découvrir des emprunts non identifiés. Ainsi, alors que l'Héraclès ne figure pas dans le relevé d'A. Tuilier, nous avons identifié (grâce aux facilités offertes par le $T L G$ ) un emprunt intéressant : le premier hémistiche de Her. 486 est identique à celui de Ch. P. 1313, lequel est à son tour proche du second hémistiche de Her. 1408. De surcroît les mots

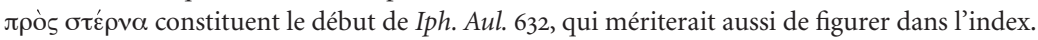

10. Sur le problème complexe de l'authenticité grégorienne de l'œuvre, la bibliographie et l'historique les plus complets se trouvent dans F. Trisoglio, «Il Christus Patiens: rassegna delle attribuzioni », Rivista di Studi Classici, xxII, fasc. 3, 1974, p. 351-423. Un colloque international - auquel participait F. Trisoglio - s'est tenu à Caen en 1989 sur cette question : voir les Actes dans Kentron, 11-12, 19951996 et 13, 1997. F. Trisoglio, spécialiste de Grégoire et partisan affirmé de l'authenticité, dans son étude récente San Gregorio di Nazianzo e il «Christus Patiens» (Florence, Casa editrice Le Lettere, 1996, infra 1996 a), avance de nouveaux arguments en faveur de l'authenticité du drame en mettant en lumière la parenté conceptuelle et stylistique entre le Christos Paschôn et les œuvres du théologien (discours ou lettres aussi bien que poèmes) dont l'authenticité n'est pas douteuse, p. 11-137; dans un second temps, par la même méthode comparative, il rejette les autres attributions (byzantines) proposées (p. 141-235). Un article d'A. Tuilier, «Grégoire de Nazianze et le Christus Patiens. À propos d'un ouvrage récent », lui est consacré in REG 110, 1997, p. 632-647. 
Christos Paschôn sont de peu postérieurs à la renaissance byzantine du XII siècle - qui fut marquée par la reviviscence du texte des Tragiques -, le Chritos Paschôn présente souvent des leçons d'Euripide antérieures même à des papyrus du vi ${ }^{\mathrm{e}}$ siècle ${ }^{11}$.

Des recherches antérieures - en particulier l'examen des origines humanistes de la position hypercritique ${ }^{12}$ - nous ont convaincue que la mise en doute de l'attribution à Grégoire de Nazianze est dépourvue de fondement solide. Si l'on accepte, en accord avec la tradition manuscrite unanime, cette attribution, le centon d'Euripide est une œuvre non de l'époque byzantine, mais de l'Antiquité tardive et se situe au terme de trois siècles d'efforts accomplis par les chrétiens lettrés pour combiner l'héritage de leur culture classique et la nouvelle religion.

La théologie chrétienne est elle-même née de ces efforts qui utilisèrent les catégories de la philosophie antique pour rendre pensable la révélation chrétienne, et l'œuvre doctrinale de Grégoire de Nazianze représente une contribution particulièrement importante à cette élaboration progressive - et mouvementée - du dogme. Mais celui que la tradition de l'Église grecque nomme «le Théologien» ne s'est pas contenté des instruments qu'il avait tirés de la philosophie et de la rhétorique classiques pour exprimer dans ses discours et ses lettres le message chrétien, il a eu recours aussi au langage de la poésie, pour une part dans une perspective lyrique et autobiographique, où s'exprime son âme tourmentée ${ }^{13}$, mais aussi dans des poèmes majeurs d'élaboration doctrinale, puisant, dans les deux cas, dans la langue d'Homère et des poètes classiques, coulant ses pensées ou prières dans le moule de leur versification. Ces poèmes semblent pour une large part avoir été composés - ou au moins achevés - dans la solitude, voulue, des dernières années de Grégoire ${ }^{14}$.

Il y avait là de sa part une orientation profonde, résultant de son imprégnation par la poésie classique et de son attachement à la littérature profane, le seul bien du «monde» auquel il refuse de renoncer, proclame-t-il à la face de Julien ${ }^{15}$, résistant

11. Pour l'histoire et l'établissement du texte d'Euripide, voir A. Tuilier, Recherches critiques sur la tradition du texte d'Euripide, Paris, Klincksieck, 1968 et «La tradition textuelle du Christos Paschôn et le texte d'Euripide », Kentron, 13, 1997, p. 119-131, ainsi que F. Jouan, «Sur l'emploi des vers du Rhésos dans le Christos Paschôn», in Synodia (Mélanges Garzia), Naples, D’Auria, 1997, p. 495-505.

12. Voir l'article résultant de la communication faite au colloque de 1989: «Les humanistes et les premiers doutes sur l'authenticité du Christos Paschôn», Kentron, 11-12, 1995-1996, p. 61-72.

13. Dans son dernier ouvrage, Gregorio di Nazianzo (Rome, Tiellemedia, 1999), F. Trisoglio étudie la personnalité tourmentée de Grégoire, en particulier chap. II « La miseria morale e ontologica della vita", p. 109-134.

14. Voir à ce sujet J. Bernardi, «À propos de l'authenticité grégorienne de La Passion du Christ», Kentron, 13, 1997, p. 145-146. L'auteur situe la production poétique de Grégoire pour l'essentiel dans les années 381-390.

15. Richesse, noblesse, gloire, puissance sont au contraire repoussées (Or. 4, PG 35, 636, 1. 8). Deux discours (Or. 4 et 5, PG 35, 532-720) prennent à parti Julien avec une extraordinaire violence dans les invectives et, par la multiplicité des allusions aux mythes et à la tradition classiques, témoignent de 
à la fois au repliement de certains milieux chrétiens qui auraient volontiers anathématisé la culture classique, et, inversement, à l'hostilité de certains intellectuels restés fidèles au paganisme, qui prétendaient refuser aux chrétiens l'accès à cette même culture.

L'intensité de ces conflits s'était en effet ravivée avec l'édit de Julien, dénommé par la tradition chrétienne l'Apostat parce qu'il était revenu au paganisme. Cet ancien condisciple de Grégoire à Athènes avait interdit aux chrétiens, en 362, d'étudier et d'enseigner les lettres profanes. La mort de l'empereur, l'année suivante, fit disparaître la menace immédiate, mais son édit avait donné une impulsion décisive à la création d'une poésie chrétienne modelée par l'hellénisme ${ }^{16}$.

Plusieurs érudits chrétiens de culture grecque se mirent à composer des œuvres chrétiennes en imitant les modèles classiques, dans la seconde moitié du IV siècle: les deux Apollinaire, père et fils, eurent une activité intense: traduction, partie en vers homériques, partie en vers tragiques, du Pentateuque et de livres historiques de l'Ancien Testament ${ }^{17}$, paraphrases poétiques des Psaumes, transposition du Nouveau Testament en dialogues platoniciens. Or, avec eux surgissait une nouvelle difficulté : Apollinaire le fils et ses proches sont les tenants d'une christologie, considérée par les « orthodoxes» comme hérétique, qui refuse au Christ une humanité complète en déclarant que le Christ a pris un corps et une âme (sensitive) d'homme, mais non un intellect d'homme, le Logos divin se substituant chez lui à l'intelligence humaine $^{18}$. Les Apollinaristes utilisent, au grand dam de Grégoire et de ses

la profondeur de la culture de Grégoire, au point de représenter en eux-mêmes un véritable défi face à l'interdiction. Grégoire y exprime son attachement passionné à tout ce qui relève du $\lambda$ óyos, entendu ici au sens le plus large de «culture intellectuelle».

16. Voir, pour l'évocation de ce conflit et de ses conséquences dans la production littéraire de Grégoire, J. Bernardi, «Un réquisitoire : les invectives contre Julien de Grégoire de Nazianze », in L’Empereur Julien. De l'histoire à la légende (331-1715), Paris, Les Belles Lettres, 1978, ainsi que F.W. Norris, dans l'introduction à Faith gives fullness to reasoning. The Five Theological Orations of Gregory Nazianzen, Leyde, Brill, 1991 ; évoquant p. 12-15 les écrits de Grégoire, l'auteur, à propos de la poésie de Grégoire (sans jamais mentionner le Christos Paschôn), souligne à la fois sa dette à l'égard des modèles classiques et la profondeur de ses aperçus spirituels.

17. Leurs œuvres sont malheureusement perdues. Il n'en subsiste que quelques fragments dogmatiques en prose, très importants d'ailleurs, sur lesquels nous reviendrons. Les témoignages les plus intéressants, parce que les plus proches dans le temps, sur l'activité littéraire des deux Apollinaire se trouvent chez deux auteurs d'Histoire de l'Église, Socrate, III, 16 ( $\mathrm{IV}^{\mathrm{c}} / \mathrm{V}^{\mathrm{c}}$ siècles) et Sozomène v, 17,12 ( $v^{e}$ siècle). Ils sont à compléter par une biographie ancienne, sans doute contemporaine de la Suda c'est-à-dire du vic siècle, œuvre de Grégoire le Prêtre, PG 35, 243-304. Voir A. Tuilier, La Passion du Christ, «Introduction », p. 56.

18. C'est Socrate II, 46 qui donne ce résumé sommaire de la christologie apollinariste, que confirment d'ailleurs les réfutations de Grégoire de Nysse notamment l'Antirrheticus et Grégoire de Nazianze

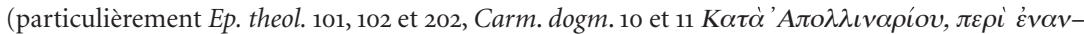

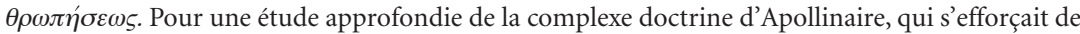
rendre compatibles logiquement anthropologie aristotélicienne (structure tripartite de l'être 
partisans, la rhétorique et la poésie pour propager leurs vues. Grégoire affirme, face à ce double danger, sa volonté de lutter sur les deux fronts : païen et hérétique ${ }^{19}$.

Dans le Christos Paschôn cette double orientation - l'acculturation du christianisme et la défense de l'orthodoxie - aboutit à une tentative littéraire extrême. Il ne s'agit plus de convertir la poésie biblique en «langue » et versification homériques, comme l'avaient tenté les Apollinaire, ou d'utiliser les formes et la langue de la poésie classique comme Grégoire le fait couramment dans le reste de ses poèmes, mais de puiser directement dans l'héritage d'Euripide des vers ou des éléments de vers, en se bornant à les insérer, avec le minimum d'ajustement, dans un contexte absolument nouveau - mais imité lui aussi du genre littéraire majeur auquel ils appartenaient ${ }^{20}-$, un drame ${ }^{21}$ ayant pour sujet le mystère central de la nouvelle religion, c'est-à-dire la passion et la résurrection du Christ.

humain $\sigma \hat{\mu} \mu \alpha, \psi v \chi \eta \dot{\eta}, v o \hat{\varsigma}$ ) et christologie (union de l'humain et du divin dans la personne du Christ), en échappant à la dichotomie platonicienne de l'âme et du corps, voir E. Mühlenberg, Apollinaris von Laodicea, Göttingen, Vandenhoeck und Ruprecht, 1968.

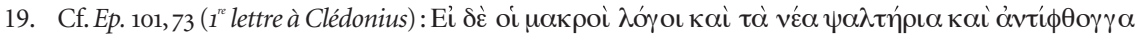

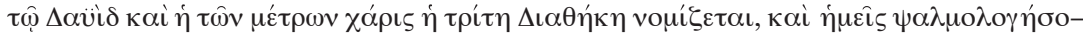

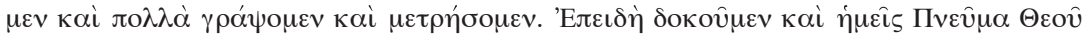

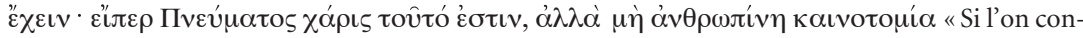
sidère comme le troisième Testament les longs discours, les Psautiers nouveaux et contradictoires de celui de David, ainsi que le charme des vers, nous aussi nous composerons des Psaumes et nous rédigerons de multiples écrits et quantité de vers. Car nous croyons, nous aussi, avoir l'Esprit de Dieu, si toutefois c'est là une grâce de l'Esprit et non une manie humaine d'innovation ». Traduction de P. Gallay dans son édition de Grégoire de Nazianze. Lettres théologiques, Paris, Éditions du Cerf (Sources chrétiennes; n²08), 1974. F. Trisoglio, Gregorio di Nazianzeno il teologo, Milan, Vita e pensiero, 1996 (infra 1996 b), rappelle, p. 177, la volonté de Grégoire de diffuser par ce moyen la foi orthodoxe et de ne pas laisser à ses adversaires apollinaristes et ariens l'exclusivité de ce moyen de prédication : il renvoie à ce propos à Carmina II, 1, 39, col. 1329-1336 (De sua vita).

20. Plusieurs études du même auteur portent sur les questions relatives au genre, particulièrement «Forme e sviluppi del monologo nella tragedia classica greca e nel Christus Patiens », Civiltà classica e cristiana, 1980. Il faut y ajouter la thèse, malheureusement non publiée, de G. J. Swart, A historicalcritical evaluation of the play "Christus Patiens », traditionally attributed to Gregory of Nazianzus, Pretoria, 1990 (DA LI 1991, 3062A), qui démontre que l'œuvre, sans parenté avec la littérature byzantine, témoigne d'une profonde connaissance du théâtre attique. C'est l'adéquation entre le langage et la forme littéraire qui, outre la dimension de l'œuvre, distingue l'exercice du centon pratiqué par Grégoire dans le Christos Paschôn d'un centon euripidéen de dimension modeste que Q. Cataudella a reconnu dans le poème (authentique) "Sur la Vertu» de Grégoire (Carm. mor. 10, v. 585-596), voir p. 446-450 de « Nuova ipotesi sulla cronologia e sull' autore del Christus Patiens », in Saggi sulla Tragedia Greca, Messine - Florence, G. D’Anna, 1969, p. 443-478.

21. La préface n'emploie pas le terme de «tragédie» mais ceux de $\lambda$ ó $\gamma$ o (discours) v. 8 , et de $\delta \rho \hat{\alpha} \mu \alpha$ (drame) v. 28. À notre avis, de ces deux termes quelque peu contradictoires, c'est le premier qui est le plus significatif. Il ne semble pas en effet que ce drame ait pu être destiné à autre chose qu'à la lecture: ses dimensions, son caractère extrêmement statique, le problème que poserait la présence - à de brefs moments - du Christ en personne sur scène s'y opposent, sans parler du déclin du théâtre et des rapports conflictuels des chrétiens avec ce divertissement. 
L'auteur lui-même, dans la préface marquée par une recherche stylistique que F. Trisoglio juge caractéristique du goût de Grégoire pour les figures comme le chiasme et le polyptote ${ }^{22}$, explicite son propos, en soulignant à l'adresse de son lecteur / auditeur l'originalité et l'audace de la combinaison d'une telle forme et d'un tel sujet:

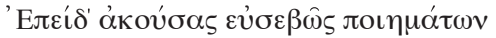

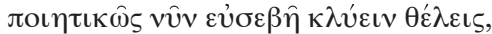

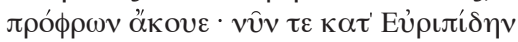

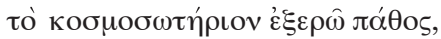

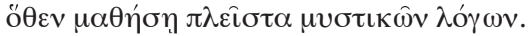

Puisque, après avoir dans un esprit de foi entendu des poèmes, tu veux maintenant dans une forme poétique écouter des sujets de foi, entends avec bonne volontéte ${ }^{23}$ : c'est selon Euripide ${ }^{24}$, que je veux maintenant t'exposer la passion qui sauve le monde. Par là tu recevras l'enseignement de très nombreux mystères.

On ne saurait rêver de meilleure justification à l'étude que nous nous proposons de mener pour tenter de saisir comment, dans le traitement du thème central de cette œuvre, se combinent, au moyen de la forme du centon euripidéen, vision tragique et dimension dogmatique du corps du Christ. Comme le laisse pressentir cette préface, l'imitation d'Euripide concerne de manière privilégiée les deux premiers volets douloureux, qui seront notre objet principal.

\section{Le corps du Christ, corps tragique}

«Le spectacle tragique est fondamentalement le spectacle de la mort et de l'homme devant la mort, sa propre mort, la mort des autres » rappelle B. Deforge ${ }^{25}$

22. F. Trisoglio, 1996a, «Appendice», p. 251, interprète ces vers «énigmatiques» comme situant le drame dans le vaste ensemble de la poésie uniformément religieuse de Grégoire et le présentant comme son couronnement. Une autre interprétation, proposée par J.-M. Mathieu lors d'une réunion de travail, voit là l'adresse à un auditeur ayant su mener de front, tout en les maintenant distincts jusqu'alors, l'apprentissage de la culture profane et celui de la religion chrétienne, qu'il serait invité maintenant à associer intimement. Quoi qu'il en soit, c'est cette intime combinaison qui nous intéresse ici.

23. Nous avons pu noter la fréquence de la racine de $\pi \rho$ ó $\rho \omega v$, terme homérique, dans la poésie de Grégoire: 22 occurrences selon l'index du TLG, contre 1 chez Euripide, 12 dans Eschyle, 2 chez Sophocle.

24. On doit relever ici une paraphrase hardie du titre donné par la tradition à chacun des Évangiles

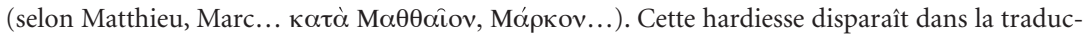
tion prudente d'A. Tuilier « à la manière d'Euripide », que suit sur ce point F. Trisoglio (La Passione di Cristo, «secondo lo stile di Euripide»). La référence initiale à Euripide exclut implicitement les interprétations figurées du corps du Christ (Église, pain eucharistique) habituelles dans la tradition ecclésiale: de fait il n'y est jamais fait allusion dans le Christos Paschôn, le " corps du Christ » y est constamment pris au sens propre.

25. B. Deforge, Le Festival des cadavres, Paris, Les Belles Lettres (Vérité des mythes), 1997, p. 13. 
en introduction de l'ouvrage dans lequel il démontre que, contrairement à une opinion trop répandue, il n’y a dans la tragédie grecque aucun «tabou » de la mort, mais qu'au contraire directement, ou indirectement par le "récit de mort», la monstration de la mort et du cadavre y est essentielle. B. Deforge rappelle ensuite $^{26}$ la position très claire d'Aristote: «L'événement pathétique est une action qui fait périr ou souffrir, par exemple les agonies exposées sur la scène, les douleurs cuisantes et blessures et tous autres faits de ce genre $»^{27}$.

On voit d'emblée combien le récit des Évangélistes constitue une matière tragique en soi. Mais l'auteur du centon a mis en œuvre une dramatisation de ce récit qui est en partie «légendaire», selon l'expression fort juste de V. Cottas ${ }^{28}$. Ce chercheur relève que les épisodes principaux du drame sont constitués d'éléments absents des quatre récits canoniques de la passion ou qui y sont à peine indiqués ${ }^{29}$. L'élément le plus original et témoignant de la créativité de l'auteur est le choix du personnage principal : les événements tragiques sont vus et vécus par la mère du supplicié, évoquée nommément dans l'Évangile de Jean seulement - et avec une très grande discrétion - parmi les femmes proches de Jésus qui se tiennent auprès de la croix ${ }^{30}$.

Le choix de cette optique pour mettre en scène les étapes d'une mort attendue, annoncée, prophétisée, et l'effacement scénique relatif - certainement inspiré par la piété - de la figure même du Christ, dont, en revanche, le corps souffrant, puis mort et enfin ressuscité, est au centre de l'œuvre, expliquent l'importance des notations corporelles dans ce drame, notations affectées d'une signification qui, au-delà de l'héritage tragique, est théologique.

Le Christ, à qui le poète donne trois fois la parole (pour deux brefs dialogues avec sa mère, au moment de sa mort et après sa résurrection, et pour une adresse à ses disciples après sa résurrection ${ }^{31}$ ), ne figure pas parmi les personnages du drame énumérés dans la liste incomplète - à la manière d'Euripide - de la préface; dans le cas du Christ toutefois, l'abstention ne peut s'expliquer par l'omission volontaire d'un personnage secondaire, mais seulement par le fait que le Christ n'est pas un personnage au sens dramatique du terme, mais un objet de contemplation.

26. Ibid., p. 28.

27. Aristote, Poétique 1492b, traduction de J. Hardy (CUF).

28. V. Cottas, Le Théâtre à Byzance, Paris, P. Geuthner, 1931 (thèse). Cette universitaire grecque s'y montra un ardent partisan de l'authenticité du drame, à une époque où une telle position n'était pas universitairement correcte.

29. Nous n'aborderons naturellement pas les problèmes d'harmonisation entre les quatre récits : dès le second siècle Tatien en particulier s'était efforcé de remédier aux divergences de détail qu'ils présentent, par l'établissement d'une sorte de concordance, le Diatessarôn, dont la version grecque est perdue.

30. Évangile de Jean 19, 25.

31. Ch. P. 727-837 (dialogue avec Marie), 2096-2107 (apparition aux deux Marie), 2504-2531 (discours aux disciples). 
Le respect religieux s'opposait évidemment à toute tentative d'analyse psychologique des souffrances du Christ. De plus, si le sacrifice volontaire, par lequel un héros assure le salut de sa communauté, est un schéma dramatique bien connu du théâtre d'Euripide, il y revêt une signification de protestation face au divin, comme le suggère de façon pénétrante R. Aélion ${ }^{32}$. Aussi est-il exclu du centon comme enjeu dramatique : le caractère volontairement consenti de la mort du Christ est sans cesse rappelée ${ }^{33}$, mais toujours associé au thème de l'obéissance à la volonté divine, dans une perspective évidemment diamétralement opposée à celle des sacrifiés d'Euripide.

Ce faisant, l'auteur réfute tout à la fois la christologie arienne qui, en majorant l'humanité du Christ, envisage la possibilité du conflit entre sa volonté et celle du Père $^{34}$ et surtout la christologie d'Apollinaire: si le Christ comme homme a accepté sa propre mort, il était doué d'une volonté qui n'émanait ni du $\sigma \omega \hat{\mu} \mu \alpha$ ni de la

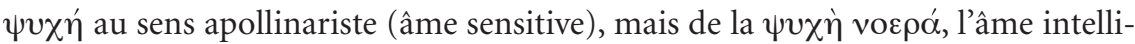
gente, considérée comme un des deux constituants de l'humanité par Grégoire de $\mathrm{Nysse}^{35}$ et par Grégoire de Nazianze lui-même, comme en témoigne cette définition donnée par lui de la volonté:

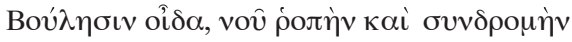

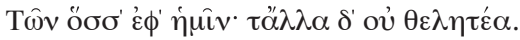

Je connais la volonté comme inclination de l'esprit et aboutissement de tout ce qui dépend de nous; pour le reste, le consentement ne nous appartient pas ${ }^{36}$.

Ce consentement du Christ est présenté comme la donnée fondamentale et le drame se concentre donc uniquement sur la réalité visible, objective de sa souffrance

32. R. Aélion, Euripide héritier d'Eschyle, Paris, Les Belles Lettres, 1983, vol. II, chap. IV, p. 124; l'auteur voit, dans le sacrifice volontaire, un thème créé par Euripide pour s'opposer à Eschyle, en montrant, contre la foi d'Eschyle en une justice divine, que «l'homme ne peut trouver le salut qu'en luimême, s'il a la force d'accepter son destin et, ainsi, de le dominer ».

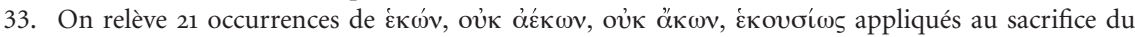
Christ et même précisément, trois fois, avec une nuance de volonté plus marquée, au moment où

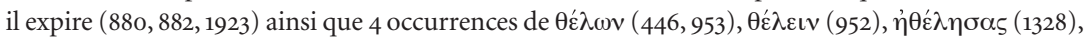
vers très important par la concordance qu'il suggère entre la volonté du Père ( $\mathrm{cf} 713$ et 885 ) et celle du Fils, par la reprise d'une même formule. Toutefois, il nous semble indispensable de rétablir dans

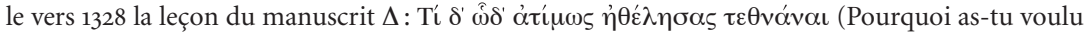
connaître cette mort ignominieuse ?), le texte actuel étant insoutenable en grec.

34. Ainsi est rejeté le dilemme formulé par certains ariens: soumission ou insoumission du Christ à son Père. Voir l'article, lisible sur internet, de B. Jeanjean, spécialiste de Jérôme : « Jérôme imitateur de Grégoire de Nazianze, une exégèse antiarienne de Grégoire de Nazianze dans la lettre 55 de Jérôme», Arob@se, vol.3, n², p. 1-15.

35. Voir les nombreuses références dans l'Antirrheticus adversus Apollinarium, vol. 3, en particulier

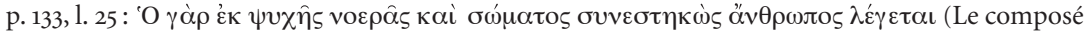
d'âme intelligente et de corps porte le nom d'homme).

36. Carm. mor., «Definitiones minus exactae », col. 948, v. 6-7. 
et de sa mort. Aussi le vocabulaire de la vue est-il omniprésent dans la première partie du drame, donnant à sa personne physique un extraordinaire relief pathétique qui permet au poète chrétien le réemploi heureux de formules tragiques. Le corps du Christ en effet porte le poids de son humanite ${ }^{37}$ : comme celui de tous les hommes, il est porteur de son identité, de sa beauté, il est l'instrument des échanges entre personnes et le lieu sur lequel s'abattent la souffrance et la mort.

\section{Réalisme et idéalisation}

La vision de ce corps est d'abord celle d'un corps souffrant avec, dans les deux premières parties, des occurrences très nombreuses du vocabulaire de la « Passion » c'est-à-dire de la souffrance endurée ( $\pi \alpha \dot{\theta} \theta 0 \zeta, \pi \alpha \theta \varepsilon \hat{\imath} v, \pi \alpha ́ \sigma \chi \varepsilon \imath v)$, mots remarquables par leur tonalité très abstraite ${ }^{38}$ mais riches de sens pour ce qui est de l'âme humaine du Christ, dépouillée de l'impassibilité ( $\alpha \dot{\tau} \alpha \dot{\theta} \varepsilon\llcorner\alpha)$ qui est l'apanage de la divinité. Ces mots relèvent du vocabulaire canonique des écrits patristiques, dans le cadre encore de la controverse avec les Apollinaristes ${ }^{39}$, controverse dont les échos sont perceptibles au vers 772, dans la supplication de Marie demandant au Christ de ne pas l'abandonner:

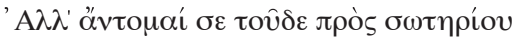

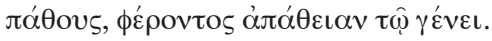

«Mais je te supplie au nom de cette passion $<$ salvatrice $>$ qui apporte $<$ l'impassibilité> au genre humain ».

La valeur théologique du terme de $\pi \alpha ́ \theta$ os l'emporte visiblement sur la représentation concrète de la souffrance. La même abstraction marque l'évocation du supplice: aucun expressionnisme, aucune trace de sensibilité baroque ${ }^{40}$ même dans l'énumération des parties du corps du supplicié, mains et pieds transpercés par les

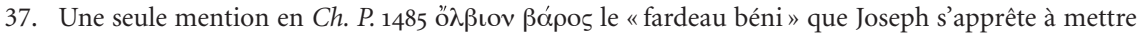
au tombeau. En revanche le terme $\pi \alpha ́ \chi 0 \varsigma$, moins positif, «l'épaisseur, la pesanteur » n’est appliqué qu'à l'humanité ordinaire $(1759,2574)$. C'est un terme cher à Grégoire de Nazianze pour évoquer la pesanteur du corps humain, opposée à la vie de l'esprit chez l'homme mais assumée par le Christ : les occurrences de ce terme, d'après l'index du TLG, sont beaucoup plus nombreuses chez lui (20) que chez Origène, Grégoire de Nysse ou Jean Chrysostome (10 au total).

38. En face des 21 occurrences des mots de la famille de $\pi \alpha ́ \theta o \varsigma$ appliqués au Christ, une seule occurrence de $\dot{\alpha} \lambda \gamma u ́ v o u \alpha \iota$, pourtant plus expressif pour désigner la souffrance physique.

39. Comme le montrent les exemples retenus par G.W.H. Lampe, A Greek Patristic Lexicon, fasc. 4, Oxford, Clarendon Press, 1965, p. 964. On peut y ajouter pour Grégoire de Nazianze le recours fré-

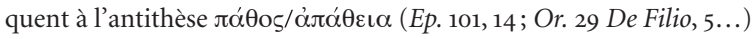

40. Le texte oppose même nettement le supplice, exécution juridique, à des formes de mort plus horribles et indignes: ainsi le chœur exprime sa crainte d'un lynchage du condamné par la foule incontrôlée (Ch. P. 485-495). 
clous, traces des outrages qui ont précédé la crucifixion, dans le récit fait par un témoin à la Vierge ${ }^{41}$, qui arrive juste après la mise en croix.

En revanche, les épisodes qui suivent la mort sont marqués de notations non pas plus réalistes, puisqu'elles relèvent du merveilleux, mais plus violentes : côté transpercé, après la mort du supplicié, par la lance du garde romain, scène commentée par les lamentations de la Vierge, qui y assiste, puis par celles du chœur, enfin racontée par le disciple Jean à Joseph, le Juif pieux venu pour assurer la sépulture $^{42}$. C'est le seul épisode dont le côté spectaculaire soit souligné, avec le double jaillissement de sang et d'eau évoqué par trois fois avec des expressions empruntées aux scènes les plus atroces d'Euripide : la mort affreuse de la jeune princesse empoisonnée par Médée, le massacre des troupeaux accompli par les Thébaines en furie dans les Bacchantes, l'égorgement de Rhésos ${ }^{43}$.

Le corps mort est ensuite, lors de la déposition de croix, puis de la mise au tombeau, décrit avec plus de réalisme que le corps souffrant, comme ensanglanté et couvert de plaies. Cependant on est frappé par la retenue de Grégoire (fidèle à son modèle classique) si l'on compare le Christos Paschôn à certaines œuvres de poésie dévote du XVII ${ }^{\circ}$ siècle présentant une vision presque érotisée du suppliciée ${ }^{44}$. L'auteur du Christos Paschôn puise dans des scènes euripidéennes douloureuses, mais marquées d'apaisement: le corps d'Hippolyte pantelant ramené devant son père, et, semble-t-il, la quête du corps dépecé et ensanglanté de Penthée dans les Bacchantes ${ }^{45}$. C'est à ces scènes que Grégoire emprunte pour évoquer d'abord la Vierge demandant à Joseph et Nicodème de soutenir en l'appuyant au creux de leurs bras, en soulevant ses bras et en redressant sa tête, le corps du supplicié qu'ils détachent de la croix, puis Joseph d'Arimathie recouvrant d'un voile la tête et le $\operatorname{corps}^{46}$. Ce dernier passage allie de façon heureuse réalisme et idéalisation sereine :

41. Ch. P. 657-681.

42. Ch. P. 1080 sq., 1101-1105, 1212 sq.

43. Ch. P. 1081-1094 et 1212-1220 empruntent à Med. 1198 sq., Bacch. 742 sq., Rhes. 790 sq.

44. Voir M. Debaisieux, «Tableaux en anamorphose : la Passion du Christ dans la poésie baroque », in Le Corps au XVII siècle (Actes du colloque de Santa Barbara, 17-19 mars 1994), Paris - Seattle Tübingen (Papers on French Seventeeth Century Literature), 1995, p. 129-140, avec d'abondants fragments. Nous sommes reconnaissante à S. Guellouz de nous avoir fait connaître ces Actes.

45. Ch. P. 1301 sq. suivant Hipp. 1431 sq. Le texte des Bacchantes comporte une lacune après le v. 1329, correspondant à l'évocation de la quête du corps démembré de Penthée, scène dont l'existence est attestée par Apsinès, rhéteur du III siècle, et les éditeurs s'appuient sur le Ch. P. à partir du v. 1256 pour tenter de la combler. Voir déjà l'édition de G. Murray, OCT, Euripides III' $^{2} 1913$ et l'article d'A. Tuilier, «La tradition textuelle du Christos Paschôn et le texte d'Euripide », Kentron, 13, 1997, qui évoque p. 128-129 le problème textuel relatif à la lacune des Bacchantes et les découvertes de fragments papyrologiques malheureusement très mutilés, mais qui ont apporté, par l'occurrence d'un terme attesté seulement à

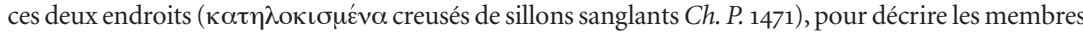
de Penthée ou du Christ, une confirmation de certaines intuitions de Kirchhoff (Philologus 8) en 1853.

46. Ch. P. 1255, 1302-1305, puis 1469-1473 (Joseph). 
«Ô visage bien-aimé, ô figure pleine de jeunesse, voici que je te couvre la tête de ce voile; et c'est dans < ces étoffes neuves $>$ que je veux envelopper tes bras et tes jambes

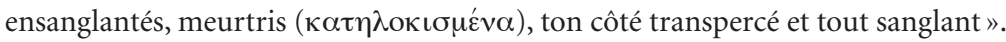

Au-delà de la description, le vocabulaire retenu pour désigner le corps du Christ est constamment poétique: on note la rareté du mot le plus neutre et le plus courant $\sigma \hat{\mu} \mu \alpha$, apte à désigner le corps aussi bien que le cadavre et, en revanche, l'emploi

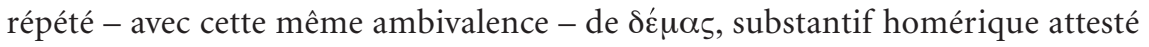
chez les trois Tragiques, mais particulièrement cher à Euripide, et, fait notable, très fréquent dans le reste de la poésie de Grégoire de Nazianze ${ }^{47}$. Ce neutre archaïque, appartenant à la racine qui signifie « construire» ${ }^{48}$, avec la valeur de «forme corporelle, stature, allure » dans la langue homérique, suggère très souvent la beauté, comme en témoigne son emploi privilégié dans des formules qui comparent pour l'allure un être humain à un immortel; chose remarquable pour la question dogmatique qui nous intéresse, le même mot peut décrire un immortel prenant un déguisement humain, se donnant l'allure de tel ou tel héros. Le sens homérique de ce mot est vigoureusement dégagé dans sa spécificité par une scholie très intéressante, sur laquelle J. Schneider a attiré notre attention, scholie dont le contenu est repris par Eustathe: les scholiastes avaient noté que déna ne désigne chez Homère que le corps vivant ${ }^{49}$, alors qu'Euripide l'utilise parfois pour désigner le cadavre.

Le choix de ce terme correspond de la part de Grégoire de Nazianze non seulement à la recherche d'une coloration à la fois homérique et euripidéenne, mais aussi à une volonté d'idéalisation, comme le manifeste le fait que parfois le poète, par une périphrase imitée de tours attestés chez les Tragiques ${ }^{50}$, accole au substantif

47. On en relève 20 occurrences dans le Ch. P. dont 8 appliquées au corps du Christ mort, 5 à l'Incarnation, dont nous parlerons plus tard. Grégoire de Nazianze emploie ce mot 70 fois, toujours en poésie; à titre de comparaison 88 exemples chez Euripide, 14 chez Eschyle et 18 chez Sophocle. Nous croyons utile de signaler qu'on ne trouve aucun exemple de ce mot chez Théodore Prodrome, un exemple seulement chez Constantin Manassès, un chez Tzétzès - mais dans un commentaire d'Aristophane. Or ce sont les auteurs byzantins auxquels on a parfois attribué le Ch. P. Par ailleurs Romanos le mélode n'en présente qu'un exemple.

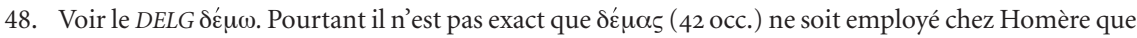
comme accusatif de relation ou avec une valeur adverbiale figée (3 ex. Il.); en deux passages de l'Odyssée il fonctionne comme régime direct: 10, 240 et 16, 174.

49. Les scholiastes appuyaient leur remarque juste sur une fausse étymologie, rattachant démas à la

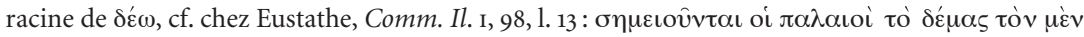

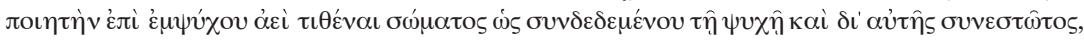

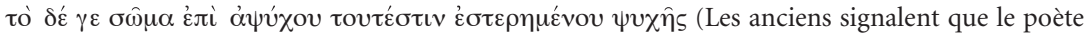
applique le terme demas au corps animé, comme étant lié et tenu ensemble par l'âme mais celui de sôma au corps inanimé c'est-à-dire privé de l'âme). Il faut d'ailleurs signaler la rareté des emplois homériques de $\sigma \hat{\mu} \mu \alpha$ (8 au total, dont 3 appliqués à des cadavres d'animaux). Le vrai nom homérique du cadavre est véкuऽ (79 осc.).

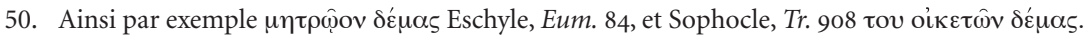




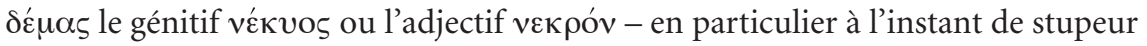

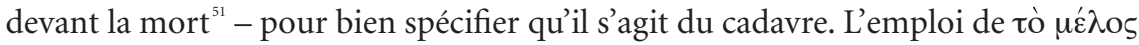
«le corps », aussi bien que du pluriel $\tau \grave{\alpha} \mu \dot{\varepsilon} \lambda \eta$ «les membres " ${ }^{52}$, relève de la même recherche de coloration poétique et il semble légitime d'en rapprocher un emploi isolé de $\sigma \chi \hat{\eta} \mu \alpha^{53}$, terme non spécifiquement poétique mais aux connotations extrêmement positives : «maintien, tenue, allure». La même tonalité poétique marque le mot le plus couramment utilisé dans le Christos Paschôn pour désigner le cadavre, c'est à dire véкuธ.

À la volonté d'idéalisation, manifestée déjà par la coloration poétique du vocabulaire désignant le corps, vivant ou mort, doit certainement être rattachée l'attention particulière portée au visage du Christ et pourtant, marque d'un vrai poète, c'est dans ces évocations que se rencontrent de fines touches réalistes. Le visage du Christ est choisi pour suggérer la souffrance de tout le corps, visible à la fois durant

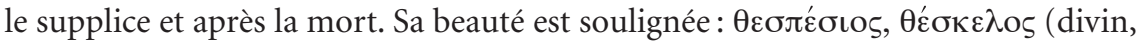
merveilleux) - termes homériques plus qu'euripidéens - sont appliqués à son aspect

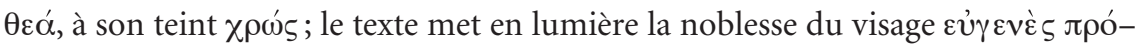
$\sigma \omega \pi \mathrm{ov}$, son expression oै $\psi \iota \varsigma$ - autrefois radieuse et maintenant sombre -, avec, dans les deux cas, des emprunts frappants par leur hardiesse, mais révélateurs d'une compréhension en profondeur d'Euripide: les paroles de la Vierge, apercevant le visage de son fils durant le supplice, ou évoquant le souvenir de son fils vivant, dans le thrène qui est l'un des plus beaux passages de l'œuvre, sont tissées des mots qu'Euripide avait mis dans la bouche de Médée contemplant une dernière fois la beauté de ses enfants, juste avant de les mettre à mort ${ }^{54}$.

Cette attention au visage inspire une notation particulièrement pathétique, audelà de son réalisme discret : l'altération du teint $\chi \rho \omega ́ s, \chi \rho o i ́ \alpha$ durant le supplice et à l'instant suprême ${ }^{55}$, avec un parallélisme poignant dans l'altération semblable et simultanée du visage de la mère sous l'effet de la douleur ${ }^{56}$. Le visage du Christ mort est admirablement suggéré dans les plaintes de la Vierge, avec de nouveaux emprunts à Médée:

51. Ch. P. 853-854: Ah! Que vois-je? C'est ton corps mort que je contemple, mon Fils, digne objet de la plus grande stupeur! Ces vers imitent Hipp. 906-907, la stupeur d'Hippolyte devant le cadavre

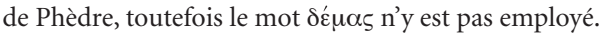

52. 6 occurrences.

53. 1 occ. Ch. P. 1323.

54. Ch. P. 472, 695, 869 proches de Médée 1043.

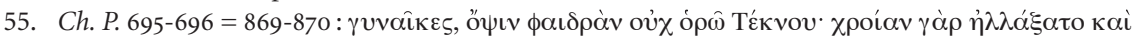
$\kappa \alpha \dot{\lambda} \lambda \lambda_{0} \xi \xi \varepsilon v o v$ «Femmes, je ne reconnais plus le visage radieux de mon Fils. Il a perdu son éclat et sa beauté extraordinaire».

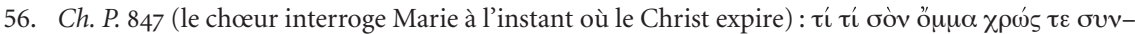

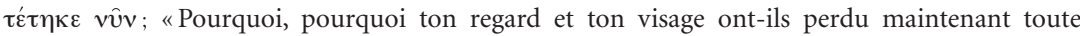
expression?». 
«Il y a un instant, je voyais encore mon fils et ses yeux s'ouvraient à la lumière. [...] Femmes, je ne reconnais pas le visage radieux de mon fils; il a perdu son éclat et sa beauté extraordinaire. [...] Comment $<$ de ces yeux muets et clos $>$ recevrai-je consolation, mère infortunée que je suis ? ${ }^{57}$.

\section{La spiritualisation du corps}

Au-delà de l'évocation du visage et du corps du supplicié, au-delà du rappel douloureux de la beauté du vivant, liés tous deux au sens de la vue, le plus intellectuel parce que le plus distant, d'autres données plus directement corporelles sont porteuses d'un pathétique puissant hérité d'Euripide, mais marqué aussi d'une empreinte toute nouvelle, celle d'un ascétisme mystique, qui essaie d'unir charnel et spirituel ${ }^{58}$ et donne un sens nouveau à la proximité physique, au rôle que joue le corps comme instrument privilégié des échanges entre personnes.

Au moment où elle aperçoit de loin son fils marchant vers le supplice, la Vierge exprime le vœu d'un dernier contact physique avec lui. Le poète chrétien a mis dans la bouche de Marie, formulant ce vœu impossible, des paroles empruntées au rôle de Jason, demandant vainement à l'impitoyable Médée de lui permettre de baiser et toucher le cadavre de ses fils. Dans le centon chrétien toutefois, ce vœu prend la forme d'une prière d'adoration :

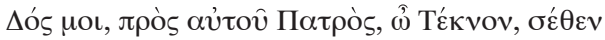

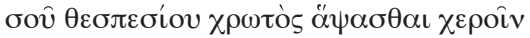

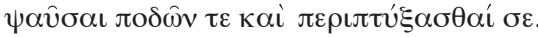

"Souffre, ô mon Fils, au nom de ton Père, que je mette les mains sur ton divin corps, que je $<$ caresse $>$ tes pieds et que je t'embrasse ${ }^{59}$.

Le vœu de Marie n'est exaucé qu'après la mort du Christ, dans une scène absente des Évangiles - qui unit avec une particulière puissance les résonances humaines et mystiques de notations corporelles, en transfigurant des données euripidéennes. Le Christos Paschôn contient, après la déposition de croix, une scène de Pietà - destinée à une grande postérité artistique ${ }^{60}$ - qui combine deux

57. Respectivement Ch. P. v. 860-861, 869-870, 906-907 répétés en 1332-1333, dans le second thrène, lors de la déposition de croix. Le vers 906, 1332 est repris de Med. 1183, où il évoquait l'évanouissement dont sort la jeune princesse pour endurer des souffrances inouïes.

58. Il serait tentant d'en rapprocher, par-delà les siècles, la formule de C. Péguy « car le spirituel est luimême charnel », dans le Porche du Mystère de la deuxième vertu, qui contient d'ailleurs une ample méditation sur l'Incarnation, la Passion et s'achève sur l'évocation de la nuit tombée sur la scène du Calvaire.

59. Ch. P. 463-465 empruntent à Med. 1400-1403.

60. V. Cottas, dans sa thèse secondaire, L'Influence du drame "Christos Paschôn" sur l'art chrétien d'Orient, Paris, P. Geuthner, 1931, développait l'argument selon lequel cette scène du Ch. P., loin de 
traitements de la maternité endeuillée empruntés à Euripide - ou à un imitateur, si l'on refuse au grand Tragique la paternité du Rhésos ${ }^{61}-$, dans lesquels les notations corporelles ont une puissance particulière.

La figure de la mère tenant dans ses bras le cadavre de son fils avait déjà été représentée par l'auteur du Rhésos, lui-même imitateur de scènes de deuil homériques ${ }^{62}$ : dans l'épilogue de sa pièce, la Muse apparaissait sur le theologeion, l'espace scénique réservé aux dieux, portant dans ses bras le corps de son fils, le héros thrace égorgé par Ulysse. Cet amour maternel se révélait pourtant tardivement : la Muse se présentait comme une mère divine, lointaine, dont le fils, abandonné par elle, dès sa naissance, dans les eaux du Strymon, son père, avait été élevé par les Nymphes des sources ${ }^{63}$.

La scène du Christos Paschôn, au contraire, est dépourvue de merveilleux et parfaitement humaine. Marie peut évoquer avec vérité, en s'adressant à son fils mort, la dimension la plus charnelle de la maternité ; cette dimension, sensible déjà dans l'expression du vers 1257 (Marie exprime le vœu en accomplissant les rites funèbres de "<baiser> la chair бó́ $\rho \kappa \alpha \varsigma$ qu'elle a nourrie $\left.{ }^{64}\right)$, est amplifiée lorsque la Vierge fait revivre, entraînée par le parallélisme cruel des situations, l'intime proximité entre mère et jeune enfant qu'évoquaient aussi Médée ou Andromaque, avec un pathétique renouvelé par la distance et l'ancienneté du souvenir : les mères d'Euripide évoquent ces scènes de la petite enfance face à de jeunes enfants menacés de mort - à l'exception de Polyxène adolescente à laquelle s'accroche sa vieille mère, Hécube -; dans le Christos Paschôn, c'est devant le corps de son fils adulte déposé sur ses genoux que la mère exhale ses plaintes:

«Donne-moi ta main droite à baiser. Ô main très chère, que j'ai souvent tenue dans la mienne, à laquelle je m'attachais comme le lierre aux branches du chêne. Ô regard aimé, ô bouche bien aimée, ô figure et noble visage de mon fils! Ô baiser très doux, $<$ ô teint divinement beau >, ô souffle très suave de mon fils! Ô parfum à l'arôme divin, dans mes malheurs je t’ai reconnu et mon cœur a été <réconforté $>$. Pourquoi as-tu voulu mourir $<$ d'une manière si ignominieuse $>$ ? Pourquoi as-tu abandonné la mère qui t’a enfanté? Hélas, puissé-je mourir avec toi mon enfant $!<$ Il vaut mieux

s'inspirer d'une iconographie préexistante, était la source absolue au contraire de toute l'iconographie de la Passion, p. 66-94.

61. Un aperçu rapide, mais suggestif, des problèmes relatifs à l'authenticité de ce drame se trouve dans l'introduction de F. Jouan au Rhésos, qui figure, conformément à la tradition textuelle, dans le vol. II consacré à Euripide des Tragiques grecs, Paris, Robert Laffont (Bouquins), 2001.

62. La scène évoque Iliade XviII 26-27, puis 70-71; la présence de Thétis tenant la tête de son fils prostré par la douleur de la mort de Patrocle est une anticipation de la scène funéraire de Odyssée 24, 47 sq., où Thétis simplement dirige la célébration des funérailles de son fils.

63. Rhes. 926-931.

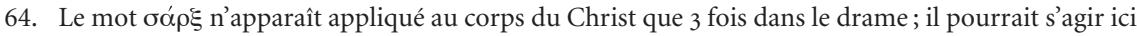
d'une expression euripidéenne, que certains éditeurs des Bacchantes restituent à la lacune, cf. supra note 45 . 
pour moi $>$ mourir que te voir mort. Comment $<$ de ces yeux muets et clos $>$ recevraije consolation? Comment < supporterai-je de te survivre $>$ ? Ô suave odeur de ton corps! Est-ce donc en vain que mon sein t'a nourri dans les langes, mon enfant? ${ }^{65}$.

L’appropriation par Grégoire de l'héritage tragique est ici particulièrement subtile. Toutes les mères en deuil du théâtre d'Euripide prêtent leur voix à Marie : la vieille Hécube, mais surtout les jeunes mères, avec cette association audacieuse de la mère victime, Andromaque, et de la mère criminelle, Médée. Ce rapprochement est d'ailleurs suggéré par le texte même d'Euripide, dans lequel on relève des ressemblances d'expression proches de l'autocenton ${ }^{66}$. Ainsi les emprunts si nombreux - et à première vue si surprenants - au rôle de Médée témoignent-ils d'une fine perception par le poète chrétien de la part d'authentique sentiment maternel qui subsiste, en dépit de sa perversion, dans le personnage de la mère infanticide.

Cependant, à travers ces plaintes si humaines de Marie percent des notations d'un ordre tout différent, mystique: la Vierge n'évoque pas seulement l'odeur suave de l'enfant, mais un parfum surnaturel émanant du cadavre, arôme qu'elle perçoit comme une consolation divine. Il y a ici encore un souvenir euripidéen très précis : celui d'Hippolyte mourant, percevant, par le parfum qui émane d'elle, la présence fugitive d'Artémis, la chaste déesse dont il est le dévot ${ }^{67}$.

La dimension mystique du lien entre la Vierge et son fils apparaît en pleine lumière lorsque ces plaintes de Marie font place à une évocation quasiment catéchétique de la conception miraculeuse et virginale de son fils, évocation d'ailleurs non dépourvue de parenté avec les tirades rhétoriques ou didactiques fréquentes dans le théâtre d'Euripide, en particulier les discours de divinités intervenant au dénouement ${ }^{68}$ :

"Le moment venu, le collège des prêtres me plaça, conformément aux prescriptions légales, sous la tutelle d'un homme sage, ce qui ne put s'accomplir sans l'intervention de Dieu et de sa Providence; ainsi raisonnablement j'ai eu en temps utile $<$ pour mon fils un défenseur et un protecteur, qui était cependant étranger à sa naissance >. Car je suis encore vierge après t'avoir enfanté et je sais bien moi-même que je demeure sans tache ${ }^{69} \ldots$

65. Ch. P. 1319-1335, imités de Med. 1070 sq., Hec. 398, Tr. 758-760. Traduction d'A. Tuilier, avec quelques modifications.

66. Voir Med. 1075 et Tr. 758, ainsi que l'insistance sur l'enfantement et l'allaitement (Med. 1029-1030 et Tr. 759-760).

67. Ch. P. 1326-1327 imité d'Hipp. 1391-1392: «Qu'est ceci ? Ô parfum à la divine haleine! Jusque dans ces maux je t'ai senti, et mon corps en a été soulagé. Elle est en ces lieux, la déesse Artémis!» (traduction revue par F. Jouan, in Tragiques grecs).

68. Voir l'épilogue par exemple d'Érechthée, Iphigénie en Tauride, Électre, Hélène, Oreste...

69. Ch. P. 1350-1360. La partie entre crochets obliques marque une modification de la traduction d’A. Tuilier, trop évasive à notre avis. Nous suivons ici F. Trisoglio, La Passione di Cristo. 
La résonance mystique des scènes de l'enfance est confirmée par le retour du thème, au moment de la mise au tombeau : la Vierge $y$ apparaît une dernière fois déchirée entre sa douleur humaine et son intuition mystique du sens de l'événement, qui inscrit la divinité dans les bornes de l'existence humaine, entre la naissance et la mort:

«Ô fils du Dieu tout-puissant, créateur de toutes choses, que peuvent les mortels sans toi ? Que peut-il leur arriver, qui ne vienne de Dieu? Hélas! Hélas! Ô mon Roi, ô mon roi, comment te pleurer ? Ô mon Dieu, ô mon Dieu, quel nom te donner? Quelles plaintes peuvent exprimer les sentiments de mon cœur? Tu es couché dans le suaire, toi que j'enveloppais naguère dans les langes $»^{70}$.

Or cette dimension mystique de la maternité est le corollaire de la virginité de Marie $^{71}$ et ces deux thèmes indissociables sont les points d'appui d'une spiritualisation du corps. Le thème de la virginitét ${ }^{72}$ est particulièrement éclatant dans le drame non seulement à travers le personnage de Marie, mais aussi à travers la constitution d'une sorte de triade, qui unit par une véritable proximité physique, traduisant les affinités spirituelles liées à la virginité, le Christ, sa mère vierge et le disciple préféré, Jean, vierge lui aussi.

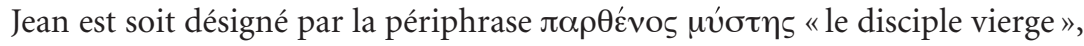
soit interpellé par le vocatif $\pi \alpha \rho \theta \varepsilon ́ v \varepsilon$ ou $\pi \alpha \rho \theta \dot{\varepsilon} v o \varsigma$ comme «vierge», à huit reprises ${ }^{73}$ dans le drame. Le passage le plus important est celui des dernières paroles du Christ, confiant sa mère à son disciple :

"I $\delta$ '

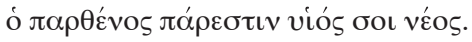

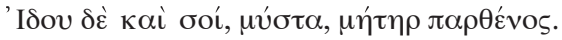

70. Ch. P. 1457-1465. Le texte du v. 1465 est corrompu, mais il nous semble impossible de conserver

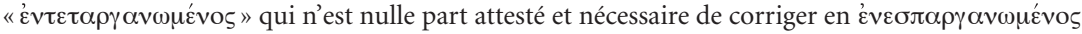
malgré la difficulté métrique (un pyrrhique au $3^{c}$ pied); ce participe est attesté 2 fois (nous l'avons vérifié dans le $T L G$ ) chez Longin et Héraclite et il semble d'autant plus s'imposer que Grégoire (comme Euripide) affectionne la figure du polyptote.

71. Virginité qui est intégrité du corps, mais aussi de l'âme, cf. v. 521 et 524 : j'ai conservé jusqu'à ce jour un corps pur $[\ldots]$ et mon âme est vierge. Le lien entre virginité et maternité de Marie dans ce drame a été étudié d'un point de vue doctrinal par J.-M. Mathieu, «C’est mon enfant, je sais comment je l'ai engendré», Kentron 13, 1997, p. 111-118, à partir du vers refrain (répété 6 fois) qu’il a donné pour titre à son article.

72. F. Trisoglio (1996 b) souligne p. 18 l'attrait de Grégoire pour la virginité; laissant de côté le poème d'implication moins personnelle «In laudem virginitatis » (Carm. mor. 1, col. 521-578), il cite Carm. de se ipso II, 1, 45, 265-276, col. 1372, l'apparition des deux vierges (Chasteté et Tempérance) qui décide de la vocation particulière de Grégoire.

73. Ch. P., préface v. 29, puis v. $728,983,1156,1166,1792,2087,2429$. A. Tuilier use d'une périphrase qui est peut-être la seule traduction admissible en français, mais qui a l'inconvénient d'atténuer le texte: «jeune homme chaste et pur». 
Ô la plus parfaite des femmes, voici que le disciple vierge est pour toi un autre fils ; et pour toi aussi mon disciple, voici une mère vierge ${ }^{74}$.

Or la proximité du disciple avec le Christ est rappelée au début du drame: dans le récit de l'arrestation du Christ, le messager souligne la fidélité intrépide

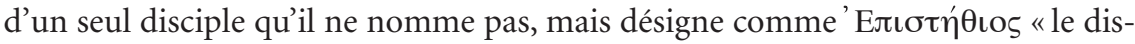
ciple qui s'était appuyé sur la poitrine du Christ» (v. 187). Jean lui-même appuie, avec une insistance significative, devant Joseph, l'autorité théologique de son enseignement - concernant la résurrection promise au genre humain, qui ne figure effectivement pas (ou de façon très marginale) dans les révélations de l'Ancien Testament - sur l'évocation de sa proximité physique avec son maître:

"Les écrits des prophètes ne m'ont rien appris à ce sujet, mais je l'ai su en me penchant sur la poitrine du maitre ${ }^{75}$; en reposant sur la poitrine du Seigneur, j'ai compris que ce serait le sort de ceux qui aiment Dieu. Comme d'un abîme, je puisais là des trésors de sagesse $»^{76}$.

On perçoit ici une dimension nouvelle du corps du Christ, devenu source d'une transfusion mystérieuse de la sagesse, pour Jean comme pour Marie, dont le chœur avait aussi évoqué l'intelligence surnaturelle des événements :

Nous savons que tu es d'une sagesse au-dessus de celle des mortels et capable, même en voyant ce spectacle, d'en comprendre la fin. Comme tout est terrifiant et, pour l'espèce des mortels, sauf pour celle qui l'a mis au monde, difficile à comprendre ${ }^{77}$.

\section{Le corps du Verbe $\delta \varepsilon ́ \mu \alpha \varsigma \Lambda o ́ \gamma o v$}

Dans tous ces passages apparaît l'idée d'un corps spiritualisé, que ce soit le corps humain dans lequel la divinité s'incarne ou que ce soit celui des créatures humaines les plus proches de la divinité. L'attention portée au corps du Christ, souffrant et mort, est en effet chargée de sens théologique. Ce corps porte certes le

74. Cette double mention de la virginité est ajoutée au texte évangélique $J n, 19,26$. Nous suivons pour ces vers la traduction de F. Trisoglio, La Passione di Cristo, qui dans la note 139, p. 75, rapproche ce passage du centon, soulignant la double virginité de Marie et de Jean, de Nonnos de Panapolis, Paraphrasis in Ioannem 19, 26-27 et de Jérôme, Ep. CxxviI, 5.

75. Allusion au récit de la Cène, $J n, 13,23$ et 25 . F. Trisoglio (1996 a) relève également dans les vers 1762 et 1764, p. 93, l'idée de la proximité physique qui permet au disciple vierge d'accéder à la connaissance des mystères. Dans les manuscrits du Christos Paschôn Jean et Marie sont désignés par les termes

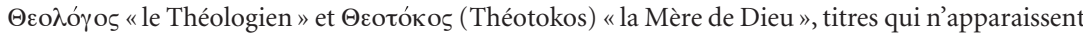
jamais dans le texte même (voir infra p. 21 et note 93 pour Théotokos).

76. Ch. P. 1761-1765.

77. Ch. P. 601-604. 
poids de l'humanité du Christ, mais il est aussi, dans son humiliation ${ }^{78}$, l'épiphanie de la divinité, épiphanie qui, par un renversement total devient éclatante dans la troisième partie du drame consacrée à sa résurrection, prémices de la divinisation et de la résurrection promises à l'humanité. Tel est en effet le sens de l'Incarnation, proclamé à plusieurs reprises dans le centon.

Le renversement de l'humiliation à la gloire est préparé : l'alliance intime du tragique et de l'espérance enracinée dans la connaissance mystique imprime sa marque à la partie centrale, consacrée à la sépulture, et assure la continuité avec la dernière partie consacrée à la Résurrection, partie dans laquelle le thème passe du ton mineur au ton majeur.

L'affirmation de la divinité du Christ donne son sens à la méditation sur son cadavre. Le corps du Christ, la personne physique du Christ est présentée comme l'image rendue visible de la divinité dans le thrène où Marie, au pied de la croix, exprime sa douleur à l'instant même de la mort de son fils :

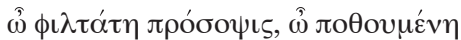

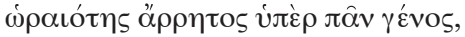

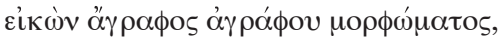

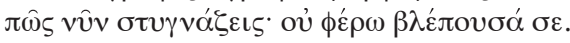

«Ô visage bien-aimé, ô beauté désirable, ineffable, <au-dessus de toute la race humaine $>$, image inexprimable $<$ de l'inexprimable forme $>$ ! Comme tu es triste maintenant! Je n'ai pas la force de te regarder ! ${ }^{79}$.

Tous les mots ici sont lourds théologiquement : la patristique grecque - et Grégoire de Nazianze tout particulièrement ${ }^{80}$ - développe l'idée que le Logos est la seule et unique image (eikôn) parfaite du Père, alors que l'homme a été créé par Dieu,

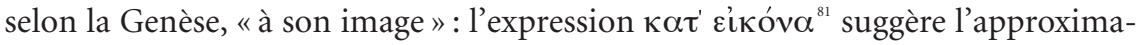
tion et l'infériorité de l'image à son modèle. Ici au contraire l'égalité de l'image et de son modèle, c'est-à-dire du Père et du Fils, ressort de la symétrie du vers et du chiasme central qui les déclare tous deux impossibles à représenter. Le terme $\mu$ ó $\rho-$ $\phi \omega \mu \alpha$ appartient, comme $\mu о \rho \phi \eta$, au lexique patristique ${ }^{82}$ de la notion de personne

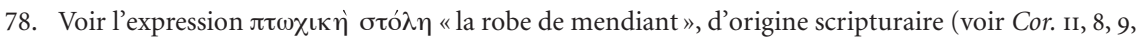

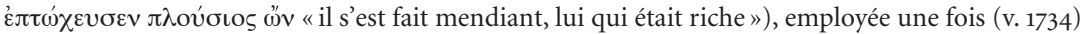
pour désigner la condition humaine assumée par le Christ et le thème de la « kénose » (le dépouillement) étudié par A. Tuilier, La Passion du Christ, «Introduction », p. 65 et 66.

79. Ch. P. 921-924.

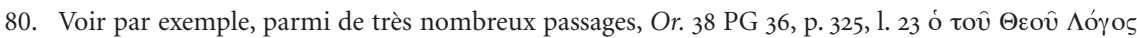

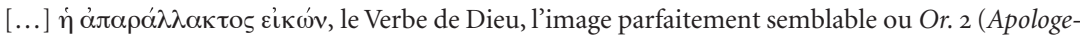

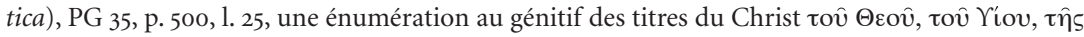

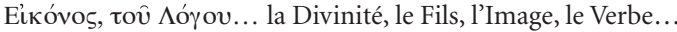

81. Gen. 1, 26 et 27; 5, 1; rappelé en Sir. 17, 3 .

82. Voir G.W.H. Lampe, A Greek Patristic Lexicon, fasc. 4, p. 884-885. 
en Dieu. Cette très belle réussite stylistique est en même temps une vigoureuse réfutation de l'hérésie arienne qui refusait d'admettre l'égalité du Père et du Fils ${ }^{83}$. L'effet est d'autant plus saisissant que le départ était purement euripidéen, l'auteur du centon s'inspirant de l'émerveillement de Ménélas devant le visage d'Hélène, dont l'innocence vient d'éclater ${ }^{84}$.

Puis, au moment même où le tombeau va se refermer, où le corps du Christ pourrait devenir un objet, sacré certes, mais objet tout de même, entouré des rites respectueux des funérailles, ce corps devient dans l'espérance de la Vierge, le corps de gloire de la fin des temps, triomphant et redevenu divin, désigné une nouvelle fois par le terme déuas, dont la noblesse est ainsi confirmée ${ }^{85}$ :

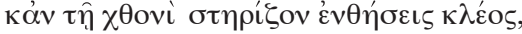

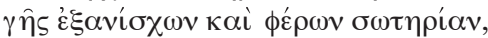

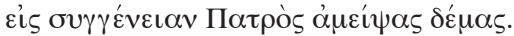

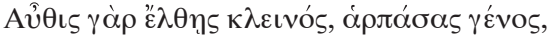

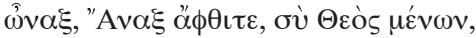

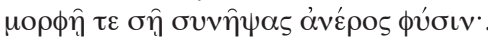

Et tu établiras fermement ta gloire sur la terre, dominant le monde et porteur du salut, après avoir transfiguré ton corps dans ta parenté avec le Père. Tu reviendras dans la gloire, après avoir emporté la race des hommes, ô Roi, Roi éternel, toi qui, tout en demeurant Dieu, as uni la nature humaine à ta personne ${ }^{86}$.

Dans cette anticipation de la fin des temps, au-delà même de la Résurrection, se trouve affirmé le sens de l'Incarnation, avec des emprunts audacieux au prologue des Bacchantes, où Dionysos expose le déguisement humain qu'il a revêtu pour exercer sa terrible vengeance ${ }^{87}$. Le lecteur familier d'Euripide ne peut manquer d'être saisi par la distance qui sépare ces deux façons d'envisager la rencontre de l'humain et du divin : le Fils a pris la nature humaine pour entraîner à sa suite l'humanité dans son retour à la nature divine. Dans la tirade prophétique de la Vierge

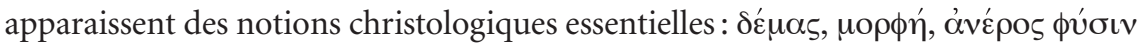
opposé à $\Theta \varepsilon o ̀ \varsigma ~ \mu \varepsilon ́ v \omega v$, renvoient au dogme de la double nature humaine et divine du Christ et de l'unité de ces deux natures en une seule personne, qu'exprimait aussi de manière elliptique un hapax désignant le Christ comme l'Homme-Dieu

83. Voir J. Liébaert, Les Pères de l'Église, vol. 1 (I'-IV siècle), Paris, Desclée, 1986, p. 135-137.

84. Hel. $636=$ Ch. P. 1531 .

85. Ch. P. 1531-1536.

86. Traduction adaptée de F. Trisoglio, La Passione di Cristo. 'E $\xi \alpha v i ́ \sigma \chi \omega$ (dont on a, semble-t-il, ici le plus ancien exemple) est certainement à rapprocher de $\hat{\varepsilon} \xi \alpha v \dot{\varepsilon} \chi \omega$ « surplomber, se dresser au-dessus de ", attesté chez les poètes alexandrins et construit avec le génitif.

87. Bacch. 4 et 54. Le vers 1536 , suivant une méthode pédagogique largement utilisée dans ce poème dramatique, est répété dans la même tirade en 1543 et 1546. 
(au génitif $\Theta \varepsilon o \beta \rho o ́ \tau o v^{88}$ ). La même idée reparaît sous forme technique et abstraite lorsque Marie, après la mise au tombeau, est saluée par Joseph d'Arimathie du titre

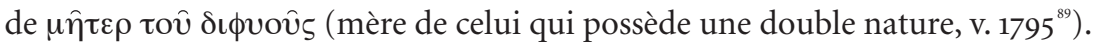

Plus avant dans le drame, l'alliance de l'humain et du divin dans la personne du Christ est puissamment suggérée par un oxymore, que F. Trisoglio curieusement ne relève pas, alors même que ces vers illustrent admirablement sa remarque sur les affinités de cette figure de style avec la théologie ${ }^{90}$. Il s'agit du passage où Marie, dans la vigile de la Résurrection, se prépare à embaumer le corps, en hésitant à obéir à des usages qui, pour le corps du Christ, n'ont aucun caractère de nécessité :

oủ $\gamma \grave{\alpha} \rho$ ưंò $\gamma \hat{\eta} \varsigma \zeta o ́ \phi o v$

$\phi \theta о \rho \alpha \grave{~ \kappa \alpha \tau \alpha \sigma \kappa \eta ́ \psi \varepsilon เ ~ \tau \iota \varsigma ~ \varepsilon i \varsigma ~ \delta \varepsilon ́ \mu \alpha \varsigma ~ \Lambda o ́ \gamma o v . ~}$

Il n'est pas possible que dans les ténèbres souterraines aucune corruption fasse pourrir le corps du Verbe ${ }^{91}$.

Il semble légitime de rapprocher de cet oxymore le titre, quatre fois décerné à

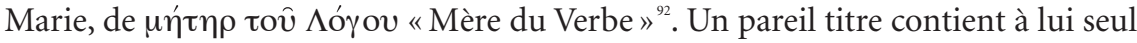
une réfutation de l'apollinarisme. Marie n'est pas seulement celle qui a enfanté le corps et l'âme sensitive d'un Christ dépourvu d'intellect (thèse apollinariste), mais elle est la mère de la deuxième personne de la Trinité. Ce titre peut apparaître comme un substitut du titre de Théotokos «Mère de Dieu ", que ni le poète dans sa préface, ni les personnages de la pièce ne lui donnent jamais ${ }^{93}$, en dépit des nombreuses salutations augustes qui lui sont adressées dans le drame. Ce titre a été officialisé seulement au concile d'Éphèse (431), donc bien après la mort de Grégoire $^{94}$. L'éclat ainsi donné à la désignation du Christ par le terme $\Lambda$ ójo (le Verbe) est caractéristique de Grégoire de Nazianze, qui l'invoque même fréquemment par le vocatif $\Lambda$ ó $\varepsilon^{95}$.

88. Marie invite les hommes qui déposent le corps au tombeau à toucher de leurs mains avec douceur le corps de l'Homme-Dieu, Ch. P. 149o. F. Trisoglio, 1996 a, p. 83, commentant cet hapax, signale dans la poésie de Grégoire de très nombreuses occurrences de l'expression de cette dualité de nature du Christ par la simple juxtaposition ou la coordination des termes «homme», «mortel» et Dieu.

89. A. Tuilier, La Passion du Christ, «Introduction», p. 66, commente cette expression et son poids dans la controverse avec les Apollinaristes.

90. 1996 a, p. 121.

91. Ch. P. 1920-1922.

92. Dès la préface du Ch. P. v. 12, puis 639, 998, puis 2580 (dans la prière finale).

93. La distribution des répliques dans les manuscrits du Ch. $P$. désigne cependant la protagoniste par le nom de Théotokos (Deipara dans les traductions latines de la Renaissance).

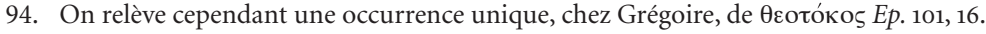

95. 32 occ., dont 8 seulement en prose. À titre de comparaison, ce vocatif n’apparaît jamais chez Grégoire de Nysse. Le Christos Paschôn en présente 6 occurrences dont 4 dans la prière finale. 
C'est comme Mère du Verbe que Marie, après avoir reçu de l'ange du tombeau l'annonce de la Résurrection, puis vu le Christ ressuscité, affirme hautement, que ni tombeau, ni corps de garde, ni pierre scellée n'auraient pu retenir

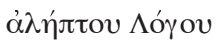

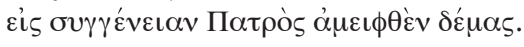

le corps du Verbe insaisissable, transfiguré dans sa parenté avec le Père ${ }^{96}$.

Cette expression de la certitude, et non plus seulement de l'espérance, fait écho au vers 1533 pour la transfiguration, tout en reprenant l'oxymore du vers 1922. La dernière occurrence de cette figure de style se trouve dans un ensemble de questions qui soulignent les contradictions, insolubles pour la raison humaine, de l'Incarnation ; l'oxymore, cette fois, est dédoublé à la fin de deux vers consécutifs :

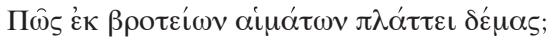

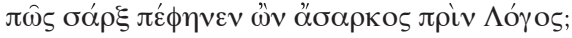

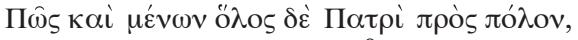

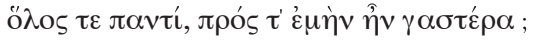

Comment peut-il prendre corps d'un sang mortel? Comment le Verbe s'est-il manifesté comme chair, lui qui était auparavant sans chair? Comment, en demeurant tout entier près de son Père dans les cieux et tout entier en tout l'univers, était-il en mon $\operatorname{sein}^{97}$ ?

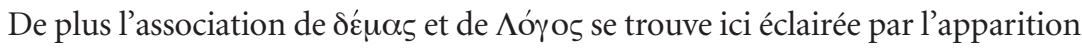
du mot oó $\rho \xi$ «chair» qui n’a été jusque-là appliqué qu’une seule fois au corps du Christ, avec une valeur banale (au pluriel) ${ }^{98}$. Les questions que formule Marie sont des variations sur un texte scripturaire essentiel pour la christologie, le prologue de l'Évangile de Jean:

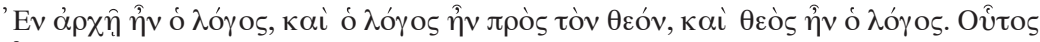

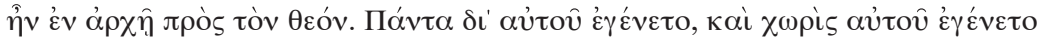

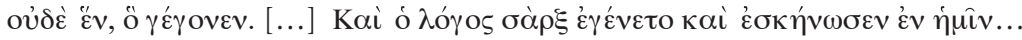

«Au commencement le Verbe était et le Verbe était avec Dieu et le Verbe était Dieu. Il était au commencement avec Dieu. Tout fut par lui et sans lui rien ne fut. [...] Et le Verbe s'est fait chair et il a demeuré parmi nous ${ }^{99} \ldots$

Le terme de «chair» est la transposition d'une expression hébraïque qui, comme le rappelle le lexique de Lampe, désigne l'homme «naturel», dans sa fragilité, par

96. Ch. P. 2393-2396, avec la reprise en écho de 1533.

97. Ch. P. 2405-2408. Traduction modifiée suivant F. Trisoglio, La Passione di Cristo.

98. Cf. note 64 .

99. Traduction de la Bible de Jérusalem. 
contraste avec ce qui est divin ou angélique, non pas le corps seulement. Même si le terme hébraïque ne se réduit pas à une figure métonymique, un commentaire d'Augustin dégage clairement les enjeux du débat théologique entamé au cours du IV siècle et qui ne devait être tranché qu'au concile de Chalcédoine (451) :

«<L'Écriture > appelle souvent «chair» l'homme lui-même, c'est-à-dire la nature de l'homme, prenant la partie pour le tout. [...] Et c'est ainsi qu'il faut comprendre: "Et le Verbe s'est fait chair », c'est-à-dire s'est fait homme; et certains interprètent faussement ce passage en pensant que le Christ n'avait point d'âme humaine ${ }^{100}$.

De la double nature du Christ et de l'authenticité de son humanité, attestée par sa passion et sa mort, dont les effets sont visibles sur son corps, dépendent le sens de la Résurrection et le sort de l'humanité appelée à la même transfiguration ${ }^{101}$. Ce thème occupe la troisième partie et, conformément aux données évangéliques - même s'il y a contamination de certains épisodes -, l'accent est mis sur la réalité, cette fois encore accessible aux sens de la vue et du toucher, du corps du Christ ressuscité, se manifestant sous une nouvelle apparence ${ }^{102}$, mais faisant constater à ses proches qu'il n'est pas un esprit ( $\pi v \varepsilon v \hat{v} \mu \alpha)$, qu'il a un corps humain composé de chair et d'os ${ }^{103}$.

Entre la première apparition du Christ aux deux Marie et l'apparition finale au groupe des disciples, prend place un long épisode ${ }^{104}$ très curieux tiré d'un apocryphe, les Actes de Pilate, dans lequel le corps du Christ est traité en négatif: c'est l'absence de ce corps qui est au centre des débats humains, objet de soupçons réciproques des disciples et des responsables juifs, ces derniers étant accusés d'avoir effectué une démarche auprès de Pilate pour l'inciter à accréditer, contre le témoignage des gardes, la thèse du vol du corps par les disciples. La finalité, difficile à saisir, de cet épisode est peut-être de rehausser l'événement véritable, au-dessus des petitesses humaines, mais certainement aussi de marquer le passage de ce qui relève de la perception (la souffrance et la mort) à ce qui relève de la foi, saut qui doit surmonter l'obscurité et le refus.

Cette dernière partie du Christos Paschôn fait particulièrement apparaître les limites de l'exercice littéraire auquel s'est livré Grégoire et qui est resté sans postérité; ces limites ne tiennent pas à la forme du centon, puisque le poète continue jusqu'à la prière finale ses emprunts à la tragédie d'Euripide. Mais ces emprunts, dont nous ne rendrons pas compte car ils ne concernent plus le corps du Christ, sont plus périphériques: rapprochements multiples et étendus entre le cadre nocturne du Rhésos et de certaines scènes des Bacchantes et les scènes de la nuit de la Résurrection.

100. Cité de Dieu xiv, ch. II. Traduction de C. Salles (Paris, Gallimard (Pléiade) 2000).

101. Cette transfiguration est annoncée par Jean à Joseph, Ch. P. 1756-1760.

102. Ch. P. 2094-2096 et 2451-2452.

103. Ch. P. 2505-2511.

104. Ch. P. 2174-2388. 
Le caractère périlleux de la tentative ne tient pas simplement au fait même du dénouement heureux de l'œuvre chrétienne, qui amenait certains ${ }^{105}$ humanistes à la qualifier de «tragédie-comédie» : on sait bien que plusieurs tragédies d’Euripide présentent des dénouements heureux. Mais le bonheur accordé à Ion et à sa mère, ou bien à Hélène et Ménélas, apparaît comme une lumière isolée dans un univers de ténèbres. Le dénouement heureux du Christos Paschôn concerne en puissance toute l'humanité, ruinant l'idée même du tragique, puisque la souffrance et la mort sont surmontées.

Pourtant cette espérance ne prend tout son relief que sur le fond de tragique authentique de la Passion. L'équilibre entre le tragique et l'espérance est maintenu à travers la figure de la mère, torturée en dépit de sa prescience mystique, dans les deux premières parties de l'œuvre, jusqu'à la mise au tombeau. Pour un lecteur familier d'Euripide, cette première moitié est celle qui contient le plus de réussites poétiques. Cependant si l'on se rappelle que Martin Luther a pu interdire toute représentation théâtrale de la Passion, de peur que le spectateur ne regarde la mort du Christ comme une injustice plutôt que comme un signe de la miséricorde divine $^{106}$, on est davantage en mesure, à la lecture de l'œuvre, de rendre justice à la sûreté doctrinale, marque d'un grand théologien, avec laquelle l'auteur du Christos Paschôn a évité cet écueil : il offre à son lecteur une méditation authentiquement tragique de la Passion et pourtant d'une orthodoxie militante, méditation qui témoigne d'une intime compréhension du tragique euripidéen et suggère par là même qu'il n'y a pas d'abîme infranchissable entre l'anthropologie du poète païen et l'anthropologie chrétienne qui la sublime.

F. Trisoglio, lors du colloque de Caen, résumait de façon suggestive le sens de la composition du Christos Paschôn, lorsqu'il nous disait que le poète chrétien avait voulu «baptiser» les vers d'Euripide, comme les bâtisseurs chrétiens avaient «baptisé » les pierres des sanctuaires païens, nous donnant pour exemple non pas les édifices ruinés et pillés, mais le temple d'Athéna parfaitement conservé qui constitue l'ossature de la cathédrale de Syracuse.

Michelle LACORE

Université de Caen Basse-Normandie

105. Mais non pas tous: ainsi J. Parente, «The Development of Religious Tragedy: The Humanist Reception of the Christos Paschôn in the Renaissance », SCJ 16, 1985, p. 351-368, signale p. 361 que, dans un commentaire de la Poétique d'Aristote, l'humaniste Robortellus attirait l'attention sur le dénouement heureux de plusieurs tragédies d'Euripide.

106. Ce refus est signalé par J. Parente, ibid., p. 362. 